\title{
Accuracy of Cartosat-1 DEM and its derived attribute at multiple scale representation
}

\author{
Samadrita Mukherjee ${ }^{1}$, Sandip Mukherjee ${ }^{2, *}$, A Bhardwaj $^{1}$, \\ ANIRBAn MUKHOPADHYAY ${ }^{3}, \mathrm{R}$ D GARG ${ }^{4}$ and S HAZRA ${ }^{3}$ \\ ${ }^{1}$ Indian Institute of Remote Sensing, Indian Space Research Organisation, Dehradun 248 001, India. \\ ${ }^{2}$ Department of Natural Resources, TERI University, New Delhi 110 070, India. \\ ${ }^{3}$ School of Oceanographic Studies, Jadavpur University, Kolkata, India. \\ ${ }^{4}$ Department of Civil Engineering, Indian Institute of Technology, Roorkee 247667 , India. \\ ${ }^{*}$ Corresponding author.e-mail: sandip.iirs@gmail.com
}

Digital Elevation Model (DEM) provides basic information about terrain relief and is used for morphological characterisation, hydrological modelling and infrastructural studies. This paper investigates the accuracy of DEM and its derived attributes in multiple scales. This study was carried out for a part of Shiwalik Himalaya using Cartosat-1 stereo pair data. DEM at various cell sizes were generated and information content was compared using mean elevation, variance and entropy statistics. Various post-spacing DEMs were validated to understand variation in vertical accuracy along different scales. The vertical accuracy $(3.14-7.24 \mathrm{~m})$ is affected in larger spacing DEM and elevation is underestimated. Slope of terrain also has similar impacts. The DEM and slope accuracy are also affected by the terrain roughness while assessing coarser grid size.

\section{Introduction}

Digital Elevation Model (DEM) is a quantitative representation of the Earth's surface and it provides basic information regarding the terrain relief (Guth 2006). DEMs and its derived attributes are important parameters for information extraction or assessment of any phenomena or process using terrain analysis (Wolock and Price 1994; Holmes et al. 2000). These are pre-requisite in different applications such as modelling water flow (Jain and Singh 2003), mass movement (Iwahashi et al. 2003), creation of relief maps (Fraser et al. 2002), natural hazards (Vassilopouloua et al. 2002; Huggel et al. 2008) and many others. The outcomes of model or analysis depend on the accuracy of DEM (Zhang and Montgomery 1994; Januchowski et al. 2010; Gómez Gutiérrez et al. 2011). The information required to characterize terrain relief can be derived from DEM in terms of primary and secondary attributes. The primary attributes, which can be derived from DEMs are slope, aspect of slope, profile curvature and catchment area. The secondary attributes are upslope area, topographic index, stream power index, radiation index and temperature index (Gallant and Wilson 1996; Wilson and Gallant 2000a, b).

Generation of DEMs can be carried out using different techniques such as photogrammetric method using stereo data (San and Suzen 2005; Hohle 2009), interferometry (Kervyn 2001), airborne laser scanning (Favey et al. 2003), aerial stereo photograph (Schenk 1996), topographic surveys (Wilson and Gallant 2000a, b) and interpolation of contour maps (Taud et al. 1999). Like any spatial dataset, DEMs are also subjected to different types of error

Keywords. DEM accuracy; grid size; scale; Cartosat-1; terrain roughness; entropy. 
such as gross errors during data collection (Rodgriguez et al. 2006), deficient orientation of stereo images (systematic error) when photogrammetrically determining elevation values (Mukherjee et al. 2011), and some unknown combinations of errors (random error) which cannot be avoided. The other issues related to DEM accuracy are grid spacing and interpolation techniques (Mukherjee et al. 2013a).

To carry out any global/regional level simulation study, small scale DEM representation is required, but for local studies large scale representation is necessary to achieve the reasonable accuracy. When the Earth surface is represented in small scale DEM, generalization effect is higher and the vertical accuracy is affected. Attempts have been made to examine the effect of DEM accuracy and grid size on the hydrological simulation (Brasington and Richards 1998; Wu et al. 2008; Dragut and Eisank 2011). In the present study, accuracy of DEM is evaluated with respect to grid size. The study area is represented in multiple scale
DEMs and validated to understand variation of vertical accuracy.

\section{Study area and datasets}

Western part of Shiwalik Himalaya is taken as the study area which is geographically situated between $30^{\circ} 8^{\prime} 30^{\prime \prime}-30^{\circ} 27^{\prime} 3^{\prime \prime} \mathrm{N}$ and $77^{\circ} 43^{\prime} 2^{\prime \prime}-$ $78^{\circ} 2^{\prime} 52^{\prime \prime} \mathrm{E}$ (figure 1). The study area encompasses part of Dehradun, the capital of Uttarakhand in India. The study is undertaken using Cartosat-1 stereo data. Size of the acquired scene is $27 \times 27 \mathrm{~km}$. Geomorphologically higher relief variation is seen in the study area. The lower middle part of the area is significantly rugged and dominated by ridge. Due to steep slope, the area is dissected by number of small channels. The northern part of this area is foothill and central part of the terrain is undulated but southern part is completely flat. The study area is covered with forest and scattered forest blanks.

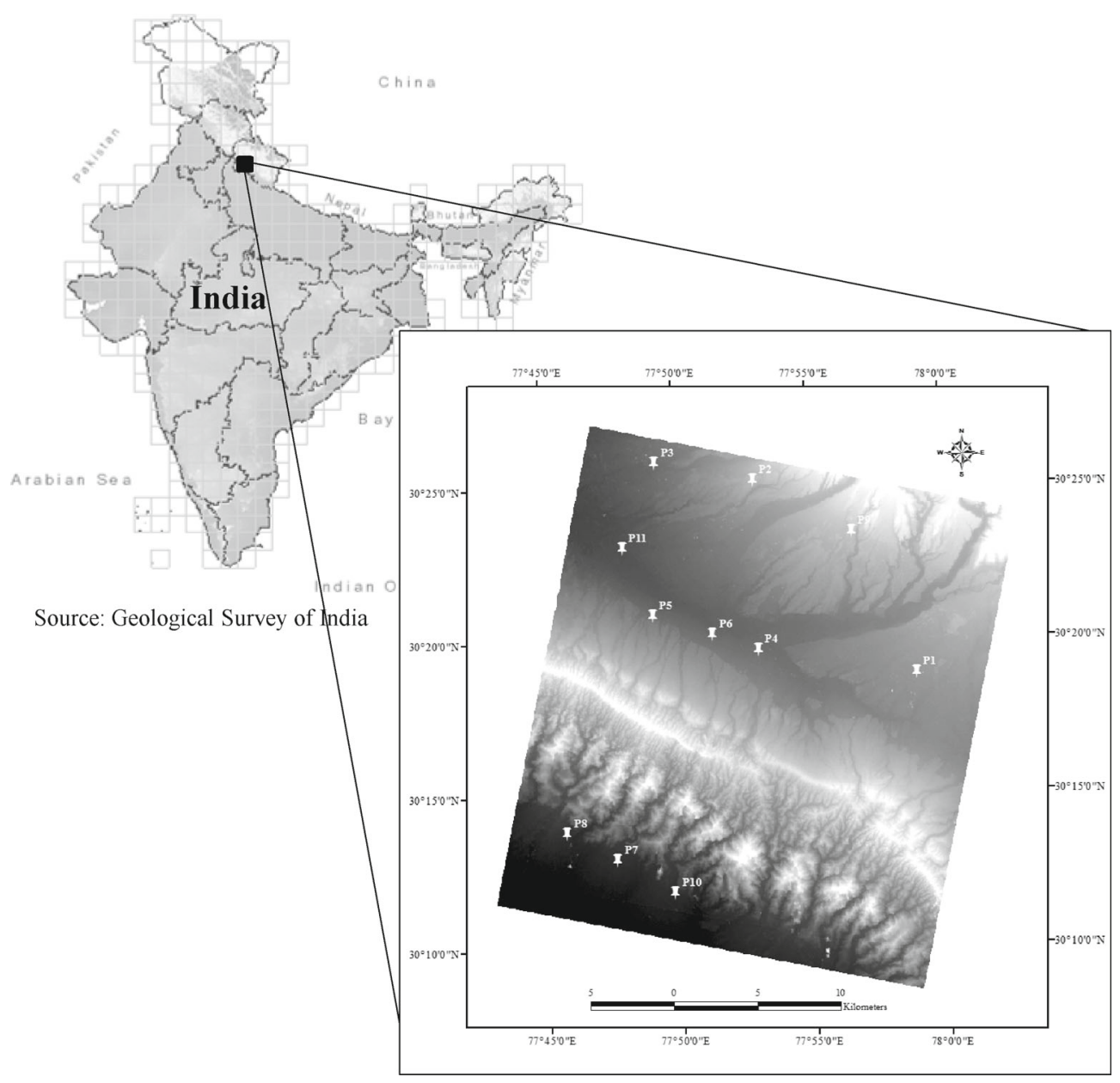

Figure 1. DEM showing the extent of study area. The lower middle part is highly dissected by the rivers, and the terrain is rugged. The middle part is the Dun valley and foothill zone. The distribution of 11 GCPs used for validation is shown here. GCPs are not taken in the highly rugged terrain and the dense forest area due to inaccessibility. 
High resolution $(2.5 \mathrm{~m})$ Cartosat- 1 data of 2 October 2005 (path/row is 0526/0258) was used in this study. Cartosat-1 satellite has a forward (F) and aft (A) panchromatic camera which gives along track stereo, with a tilt in flight direction of $\pm 26^{\circ}$ and $\pm 5^{\circ}$, respectively (Baltsavias et al. 2007; Mukherjee et al. 2013b). Cartosat-1 stereo data comes with Rational Polynomial Coefficients (RPCs). RPCs comprise of satellite ephemeris as well as GCPs (ground control points). It allows the satellite vendor to withhold certain confidential sensor information without denying public use of the satellite imagery (Fraser et al. 2006). LPS ${ }^{\circledR}$ software (9.3 version) was used for orientation of the stereo block. Thirty-one well distributed GCPs over the scene were collected using DGPS (Differential Global Positioning System) survey in Dehradun using Lieca single frequency GPS receiver. The received signals were differentially corrected with the help of base station receiver data during the post-processing of GCPs using Ski Pro software.

\section{Methodology}

The entire methodology of the study is divided into three parts; DEM generation, slope calculation and accuracy assessment. The overall methodology of the study is described in this section.

\subsection{DEM generation}

To generate a DEM, orientation of stereo pair is carried out to solve the basic problem of determining object space coordinate $(\mathrm{x}, \mathrm{y}$ and $\mathrm{z}$ ) of a point in the image space. Mainly two types of orientations are needed; interior orientation and exterior orientation. Interior orientation reconstructs the position of perspective centre of the sensor with respect to image. It usually defines the internal geometry of a camera or sensor as it existed at the time of data capture. It includes parameters for detector positions, principal point and focal length optical distortion (Grodecki and Gene 2003). Exterior orientation reconstructs the position, inclination and rotation of the sensor with respect to terrain coordinate system for each line of the data. It defines the position and angular orientation associated with an image and builds the relationship between sensor and ground. The exterior orientation parameter includes position and altitude. The GPS receiver on the satellite is used for determining the satellite ephemeris, i.e., camera position with time, star tracker and gyros on board, measuring camera attitude as function of time (Grodecki and Gene 2003). Initially stereo block is oriented with RPCs. Then GCPs are added in stereo model to avoid systematic errors. Fifteen GCPs were used as control points and 5 GCPs as check points (for estimation of block accuracy) in order to orient the stereo model. The remaining 11 GCPs were used for validation of DEMs. Location of the GCPs which were used for validation is shown in figure 1 . Using oriented stereo block, $10 \mathrm{~m}$ grid spacing DEM was generated. From the same block 30, 50, 90, 110 and $150 \mathrm{~m}$ grid spacing DEMs were also produced. The DEMs surfaces are projected to Universal Transverse Mercator (UTM) projection with zone No. 43 and WGS 84 datum.

\subsection{Calculation of slope}

The main terrain parameters derived from DEM are slope and aspect. These parameters are local description of downhill slope showing magnitude and direction of vector tangent to the downhill. In this study, only magnitude of the terrain inclination, i.e., accuracy of slope is evaluated using multiple DEMs representation. Slope at a given point on a surface is function of height values $[\operatorname{slope}(x, y)=$ $f(Z)$ ]. It is first derivative of elevation describing rate of change of elevation. Together, the slope in the $x$ direction and slope in the $y$ direction (partial derivatives of $Z$ with respect to $x$ and $y$ directions) define the gradient vector of the surface (equation 1). The maximum slope can be determined by taking the norm of this vector. On a grid DEM, slope calculation is performed using $3 \times 3$ moving window to derive finite differential. In this study, second-order finite difference was used. Four Closest Neighbours (FCN) algorithm (Guth 1995; Raaflaub and Collins 2006; Mukherjee et al. 2013a) was used for computing slope. It takes into account two orthogonal components of slope in $x$ and $y$ direction. In other words, the algorithm used four cardinal neighbours, i.e., north, south, east and west representing a second-order finite difference relationship (equation 2). This defines steepness and downhill direction.

$$
\begin{aligned}
\text { Slope } & =\sqrt{\left(\frac{d z}{d x}\right)^{2}+\left(\frac{d z}{d y}\right)^{2}}, \\
\frac{d z}{d x} & =\left(z_{8}-z_{2}\right) / 2 g \\
\frac{d z}{d y} & =\left(z_{6}-z_{4}\right) / 2 g
\end{aligned}
$$

\subsection{Accuracy assessment}

The information content of the various grid spacing DEMs are compared using entropy statistics (Shannon 1948). Various studies (Vieux 1993; 
Vieux and Farajalla 1994) suggest that aggregation or smoothing lead to the loss of information in the DEM and thus loss of entropy. It is a debatable fact that loss of entropy is a measure of DEM quality or related to error in the DEM (Wise 2012), but it is well known that entropy is related to the amount of information in a DEM and the spatial variability of the elevation values. The information statistics or entropy is calculated using following equation:

$$
I=-\sum_{i=1}^{n} p_{i}, \log \left(p_{i}\right),
$$

where $I$ is entropy, $n$ is number of possible bins in the DEM and $p_{i}$ is the proportion $i$ th bin of a DEM. Logarithm to base 10 is used in this study and thus the units for entropy are Hartleys (Wise 2012). The elevation values of a DEM are converted to the nearest integer and the entropy is calculated.

The overall accuracy of DEM is calculated using RMSE (Root Mean Square Error) and ME (Mean Error). RMSE exhibits on an average how far observed values are deviating from the assumed true value. The ME tells us whether a set of measurements consistently underestimate (negative ME) or overestimate (positive ME) the true value. The RMSE is a single quantity characterizing the error surface, and the mean error reflecting the bias of the error surface. The accuracy of 30-150 m grid spacing DEMs surfaces are estimated by comparing with $10 \mathrm{~m}$ grid spacing DEM. The equations are listed below.

$$
\begin{gathered}
\mathrm{RMSE}=\left[n^{-1} \sum_{i=1}^{n}\left(\mathrm{DEM}_{\mathrm{ref}}-\mathrm{DEM}\right)^{2}\right]^{1 / 2}, \\
\mathrm{ME}=\left[n^{-1} \sum_{i=1}^{n}\left(\mathrm{DEM}-\mathrm{DEM}_{\mathrm{ref}}\right)\right] .
\end{gathered}
$$

The accuracy of $30-150 \mathrm{~m}$ grid spacing DEM surfaces are also tested with respect to 11 GCPs and error expressed in terms of RMSE and ME.

\section{Result and discussion}

A DEM represents the details of elevation changes as per the grid spacing over the Earth surface.
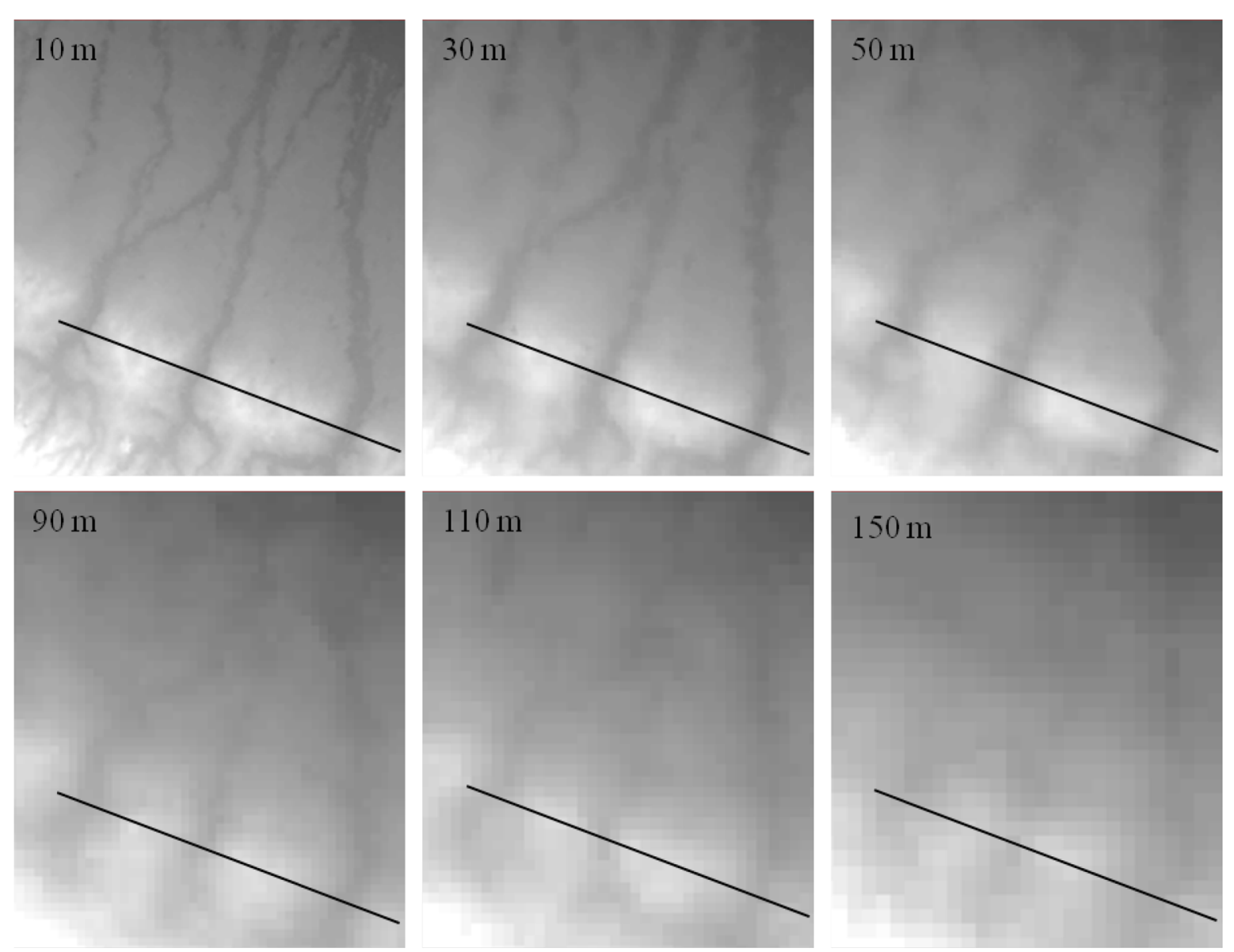

Figure 2. Terrain is represented using 10-150 m grid spacing DEM 1:80,000 scale display. Up to $50 \mathrm{~m}$ grid spacing, the major rivers are visible but $90 \mathrm{~m}$ grid spacing onwards representation of terrain morphology is extremely degraded. 
In coarse resolution, the micro level details of the Earth surface characteristics are averaged out and the surface depiction becomes generalized. Only the macro/broad roughness characteristics can be identified in coarse resolution. The generalization effect of DEM grid spacing also influences vertical accuracy of the elevation value. Part of the study area is represented in 10-150 m grid spacing (figure 2). It is found that representation of the terrain is affected due to this generalization. In $10 \mathrm{~m}$ grid spacing DEM, the minute details of the surface and small river channels are visible. But with increase in grid spacing, the small channels are hidden and only the major channels are partially visible (150 m DEM). The interpretation of the terrain morphological characteristics changes with DEM grid spacing, because the dissections of terrain by the small river channels are invisible in larger grid spacing DEM. The terrain profile of the crosssection of the same area is shown in figure 3 . It shows that the slope gradient is steep in lower grid spacing DEM. Details of the surface is averaged out in coarser grid spacing DEM and terrain undulation characteristics are also generalized. The DEM statistics of 10-150 m grid spacing DEM (table 1) shows that the mean elevation of the surface is almost constant irrespective of grid spacing. But the variance is decreasing with grid spacing which signifies that surface representation is smooth in the coarser grid spacing DEM. The entropy value is showing a declining trend in coarse grid spacing DEM. The entropy value is 6.10 for $10 \mathrm{~m}$ spacing DEM which reduced to 5.62 in $150 \mathrm{~m}$ spacing DEM. However, loss of entropy is very small. The loss of entropy is mainly because of the reduction of number of bins in coarse grid spacing DEM. It signifies the smaller number of distinct elevation values in the coarse grid spacing data and no change in their relative frequencies. The fall in entropy indicates the loss of information in the various scale DEM representation.

Table 1. Statistics derived from various grid spacing DEM (in meters).

\begin{tabular}{lccc}
\hline $\begin{array}{l}\text { Grid } \\
\text { spacing }\end{array}$ & $\begin{array}{c}\text { Mean } \\
\text { elevation }\end{array}$ & $\begin{array}{c}\text { Variance of } \\
\text { elevation }\end{array}$ & $\begin{array}{c}\text { Entropy } \\
\text { (Hartleys) }\end{array}$ \\
\hline 10 & 551.79 & 111.28 & 6.10 \\
30 & 550.67 & 108.15 & 6.00 \\
50 & 548.79 & 104.98 & 5.91 \\
90 & 546.92 & 100.01 & 5.83 \\
110 & 546.68 & 95.04 & 5.75 \\
150 & 546.47 & 91.57 & 5.62 \\
\hline
\end{tabular}

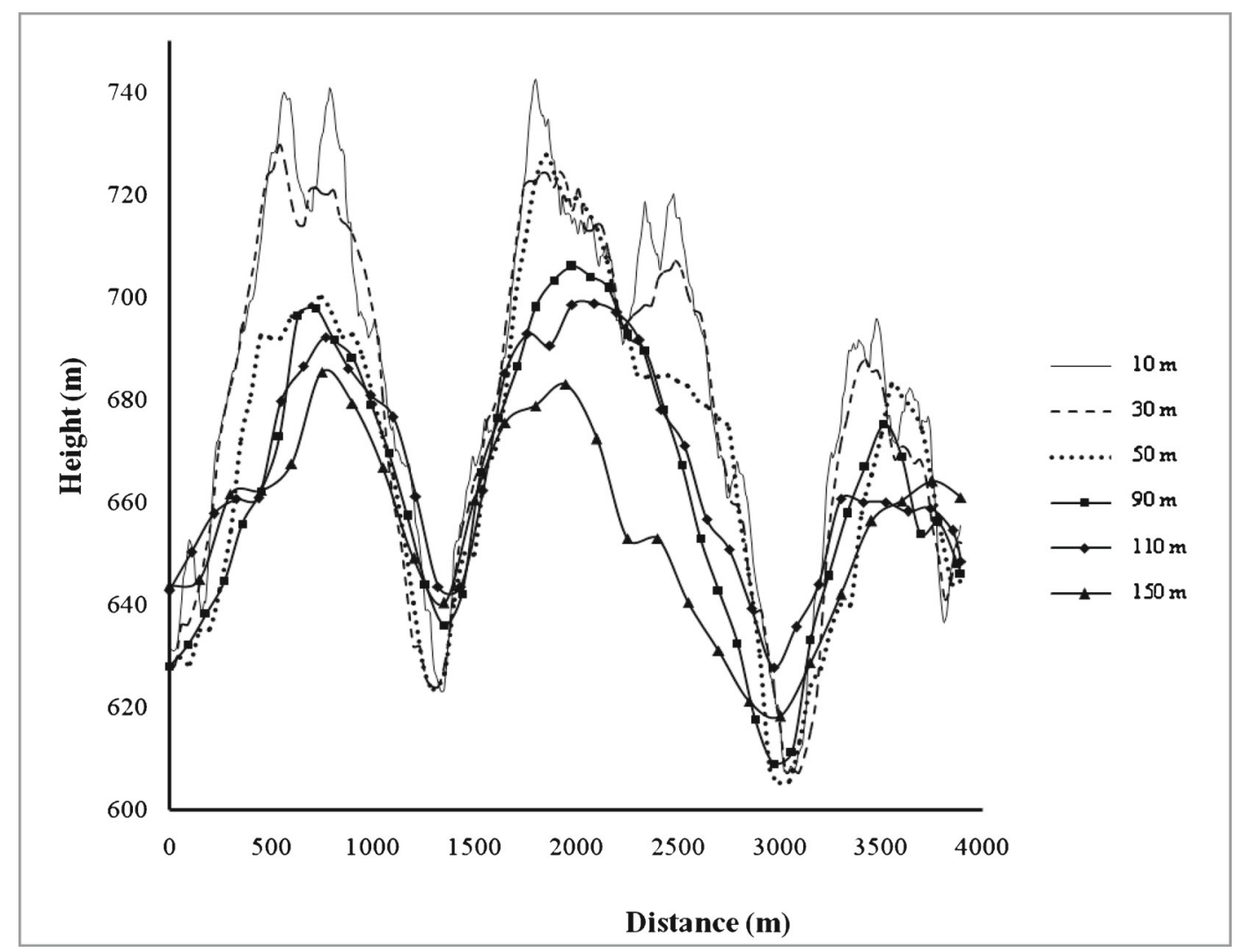

Figure 3. Terrain profile drawn along the section line marked in figure 2. 


\subsection{Accuracy of various grid spacing DEM}

Vertical accuracy of the DEM surfaces, derived in 10-150 $\mathrm{m}$ grid spacing is evaluated using 11 GCPs taken using DGPS. The elevation values of GCPs and DEMs are compared and calculated using RMSE and ME. The RMSE curve (figure 4) shows an increasing trend. The error in elevation varies from 3.14 to $7.24 \mathrm{~m}$ in $10-150 \mathrm{~m}$ spacing DEM. The mean error curve (figure 5) indicates that the elevation values are underestimated in the larger grid spacing DEMs.

The validation of DEM surface using 11 sample GPS points does not reveal the entire scenario. Hence, the $10 \mathrm{~m}$ DEM is taken as reference data and 30, 50, 90, 110 and $150 \mathrm{~m}$ DEM surfaces are validated. The validation is performed using surface to surface comparison. The RMSE varies from 7.50$15.77 \mathrm{~m}$ showing linear increasing trend (figure 6) with larger grid size. The ME (figure 7) also indicates underestimation of elevation value due to generalization effect in coarser gridded DEMs.

Terrain morphology is one of the major influencing factors in vertical accuracy of DEM. In order to

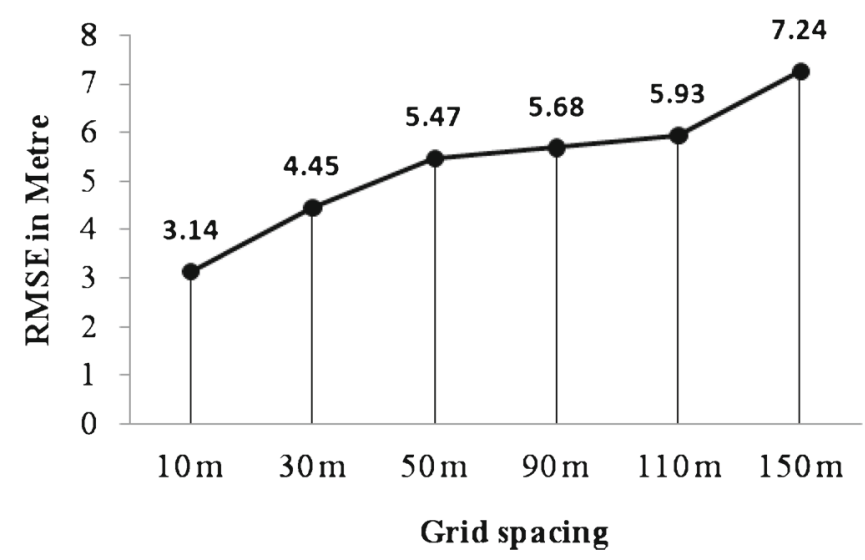

Figure 4. RMS error of DEM in various grid spacing DEM with respect to GCPs.

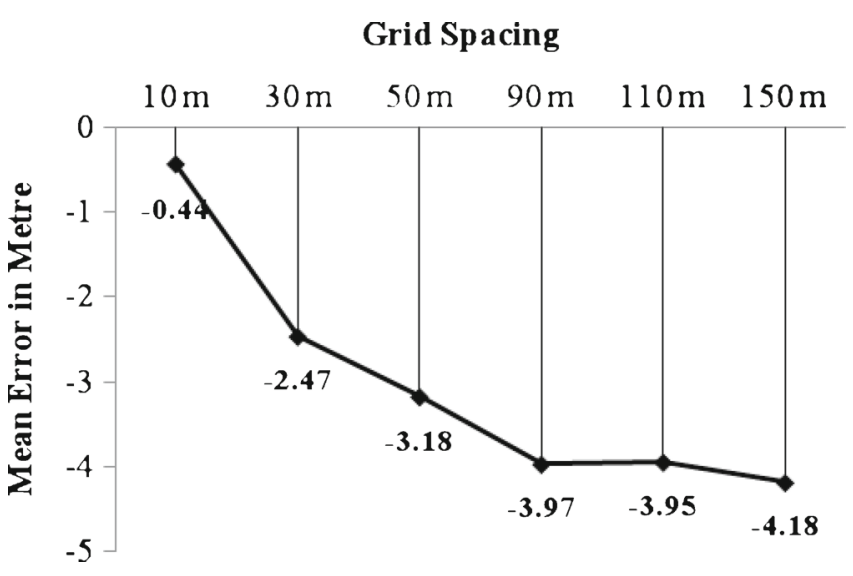

Figure 5. Mean error of DEM in various grid spacing with respect to GCPs. evaluate this, $10 \mathrm{~m}$ DEM is divided into five altitudinal zones (<400, 401-500, 501-600, 601-700 and $>700 \mathrm{~m})$. The statistical characteristics of each elevation zone is shown in table 2 . The variance of elevation and slope indicates that roughness of the terrain is higher in high altitudinal zone. The RMS error of elevation value within each zone is calculated using difference surfaces (figure 8). The vertical accuracy of DEM is affected by terrain roughness characteristics. The DEM surface is more erroneous in high altitudinal zone which is mainly due to the imperfect orientation of stereo pair in rugged terrain (Mukherjee et al. 2011). The accuracy of the surface also declines in the larger grid spacing DEM.

\subsection{Accuracy of slope in various grid spacing}

Slope is a primary terrain attribute which is derived from a DEM. It is an important parameter

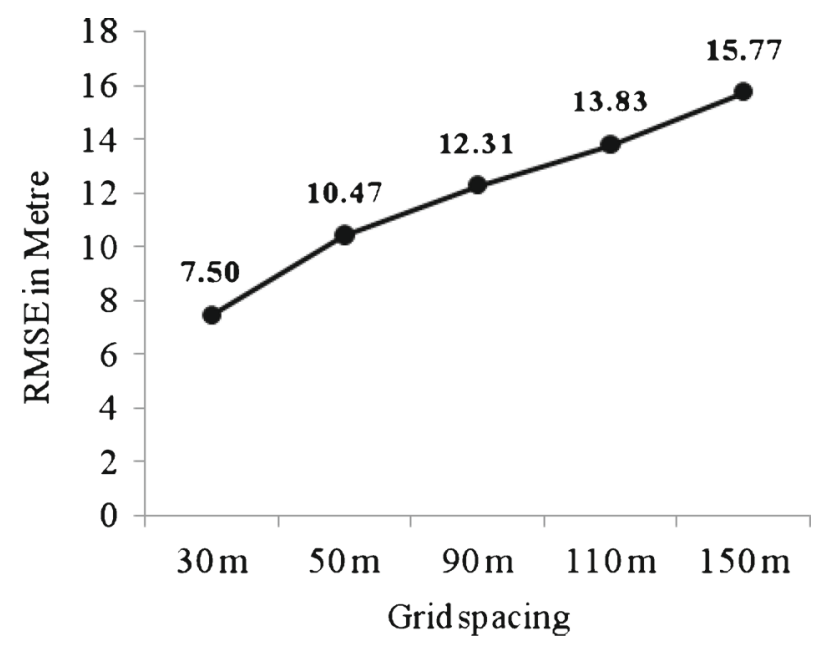

Figure 6. RMS error of various grid spacing DEM validated using $10 \mathrm{~m}$ grid spacing reference DEM.

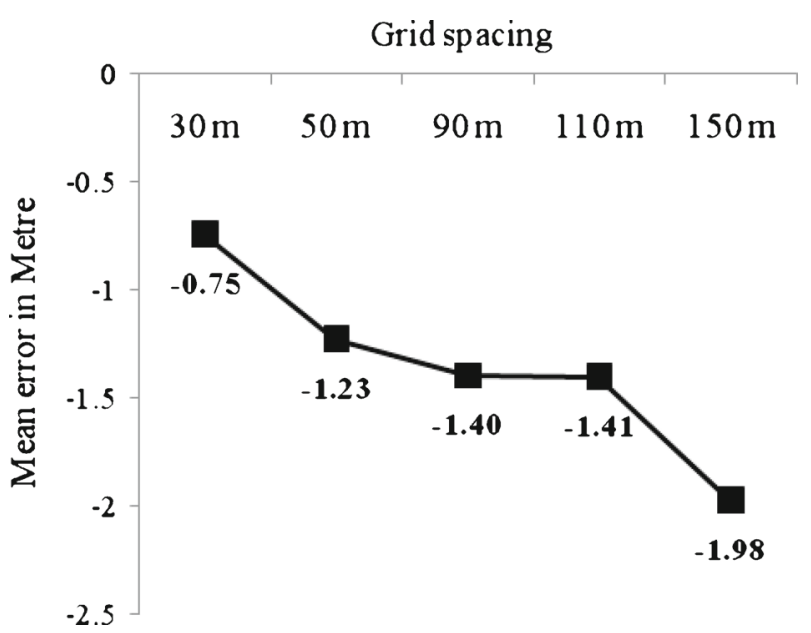

Figure 7. Mean error of various grid spacing DEM validated using $10 \mathrm{~m}$ grid spacing reference DEM. 
Table 2. Characteristics of different altitudinal zones delineated from $10 \mathrm{~m}$ grid spacing DEM (in meters).

\begin{tabular}{lccrc}
\hline $\begin{array}{l}\text { Altitudinal } \\
\text { zone }\end{array}$ & $\begin{array}{c}\text { Mean } \\
\text { elevation }\end{array}$ & $\begin{array}{c}\text { Variance of } \\
\text { elevation }\end{array}$ & $\begin{array}{c}\text { Mean of } \\
\text { slope }\end{array}$ & $\begin{array}{c}\text { Variance } \\
\text { of slope }\end{array}$ \\
\hline$<400$ & 330.66 & 15.29 & 5.97 & 6.72 \\
$401-500$ & 411.57 & 31.78 & 8.89 & 9.12 \\
$501-600$ & 511.38 & 29.41 & 9.78 & 10.70 \\
$601-700$ & 602.20 & 28.42 & 13.14 & 12.26 \\
$>700$ & 714.16 & 47.28 & 18.41 & 12.44 \\
\hline
\end{tabular}

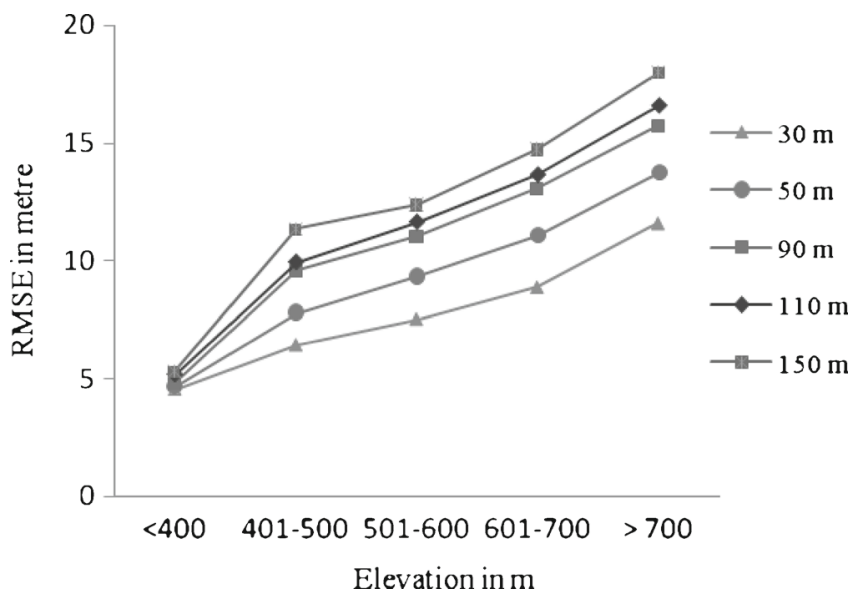

Figure 8. RMS error in elevation value is calculated with respect to various altitudinal zones.

for hydrological modelling and other applications. Slope characteristics, extracted from various grid spacing DEMs change with grid spacing of DEM (table 3). The maximum slope reduces from $75.34^{\circ}$ to $17.97^{\circ}$ while moving from $10-150 \mathrm{~m}$ grid spacing. The mean and variance of the slope also reduce very rapidly in larger grid spacing. It signifies that the slope gradient is highly affected by generalization.

Accuracy of the slope is evaluated in terms of inter-scale comparison considering $10 \mathrm{~m}$ slope surface as reference. The validation result shows that, RMSE varies from $7.06^{\circ}$ to $12.79^{\circ}$ while moving from 30 to $150 \mathrm{~m}$ grid spacing (figure 9 ). Due to the generalization effect of the elevation value, the slope estimated from large spacing DEM are affected and representation of the slope is declined. It is also revealed in the mean error plot (figure 10) which indicates that slope of the surface is underestimated when calculated from larger grid spacing DEMs.

Figure 10 shows RMS error of slope within each altitude zone. The accuracy curves of the slope suggest the decrease of slope accuracy being influenced by terrain roughness. The effect is more significant in slope surface derived from larger grid spacing. It happened because the generalization effect of DEM is higher in the rough terrain with increasing spacing. With the increase of grid spacing, the relative
Table 3. Statistical characteristics of slope derived from various grid spacing DEM in degree.

\begin{tabular}{lccrr}
\hline $\begin{array}{l}\text { Grid } \\
\text { spacing }\end{array}$ & Minimum & Maximum & $\begin{array}{c}\text { Mean of } \\
\text { slope }\end{array}$ & $\begin{array}{c}\text { Variance } \\
\text { of slope }\end{array}$ \\
\hline 10 & 0.003 & 75.34 & 12.02 & 11.71 \\
30 & 0.002 & 64.64 & 6.65 & 7.08 \\
50 & 0.001 & 46.38 & 5.00 & 5.18 \\
90 & 0.003 & 29.29 & 3.72 & 3.75 \\
110 & 0.002 & 30.64 & 3.35 & 3.24 \\
150 & 0.020 & 17.97 & 2.85 & 2.57 \\
\hline
\end{tabular}

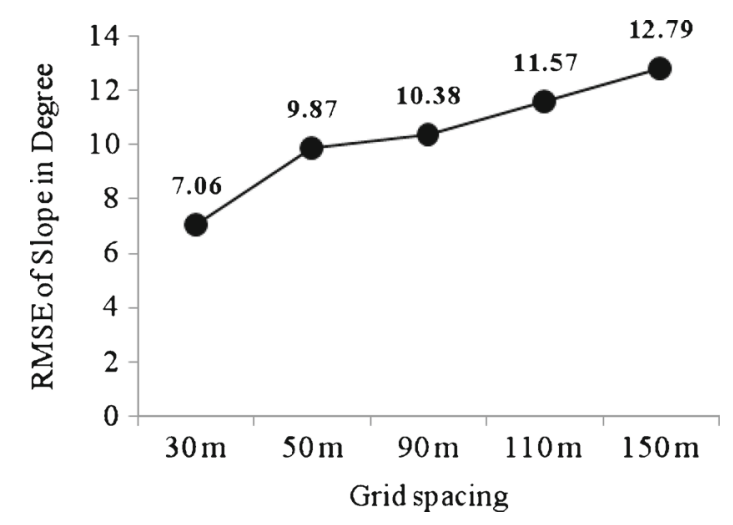

Figure 9. Accuracy of slope in various grid spacing.

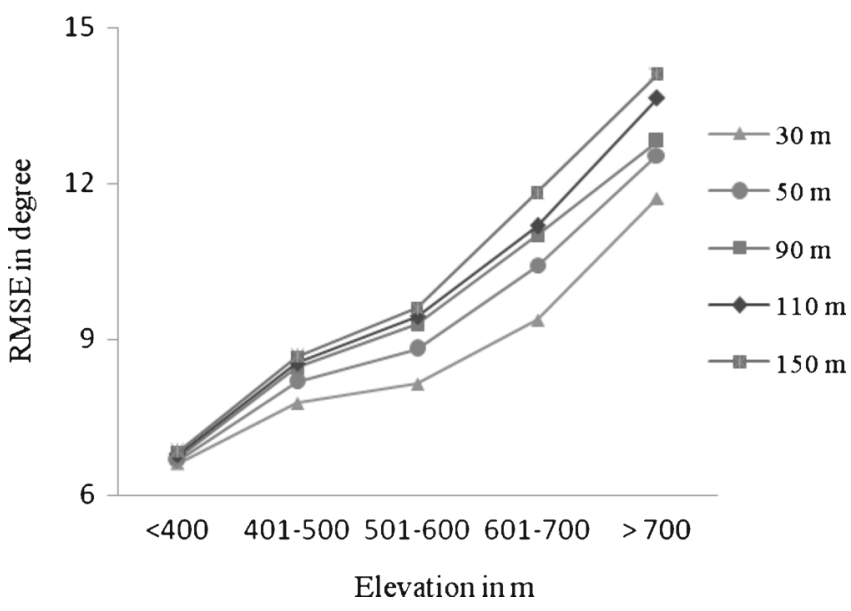

Figure 10. RMS error of slope calculated from various altitudinal zones.

relief of an area with its neighbourhood decreases and slope calculation becomes more erroneous.

\section{Conclusion}

The result achieved from the statistical analysis performed in this study to evaluate the accuracy of DEM in multiple scale representations suggests that representation of the surface using DEM is highly influenced by scale. Details of the terrain 
variation reduces in the small scale representation. The elevation values represented in finer grid spacing DEM are averaged out in coarser grid and the surface becomes smooth. Due to this reason, the mean elevation remains constant and the variance reduces as grid spacing increases. The loss of entropy in coarse grid spacing DEM signifies the information loss. Vertical accuracy of the DEM suffered from scale effects and surface elevation is underestimated. The terrain roughness characteristics influence the DEM accuracy while moving from smaller to larger grid spacing. Slope calculation is also affected by the multiple scale DEM representation. Accuracy of the slope reduces and surface slope is underestimated in larger spacing DEM. The terrain morphology also has an impact on slope calculation along with grid spacing. With an increase in grid spacing and roughness of the terrain, the surface representation will become more erroneous. Further study can be carried out in different regions with varying terrain characteristics. Also the evaluation of primary and secondary attributes of DEM in various scales would be interesting.

\section{Acknowledgements}

Authors are thankful to Indian Institute of Remote Sensing, Dehradun for providing the dataset for this study. Authors are also thankful to Dr $\mathrm{P} \mathrm{K}$ Joshi for valuable comments to improve the manuscript.

\section{References}

Baltsavias E, Kocaman S and Wolff K 2007 Geometric and radiometric investigations of Cartosat-1 data; ISPRS Hannover Workshop 2007, High Resolution Earth Imaging for Geospatial Information, Hannover, Germany, May 29-June 1.

Brasington J and Richards K 1998 Interactions between model predictions, parameters and DTM scales for topmodel; Comput. Geosci. 24(4) 299-314.

Dragut L and Eisank C 2011 Object representations at multiple scales from digital elevation models; Geomorphology 129 183-189.

Favey E, Geiger A, Gudmundsson G H and Wehr A 2003 Evaluating the potential of an airborne laserscanning system for measuring volume changes of glaciers; Geografiska Annaler: Series A Physical Geography 81(4) 555-561.

Fraser C S, Dial G and Grodecki J 2006 Sensor orientation via RPCs; ISPRS J. Photogramm. Remote Sens. 60 182-194.

Fraser C S, Baltsavias E and Gruen A 2002 Processing of IKONOS imagery for submeter $3 \mathrm{D}$ positioning and building extraction; ISPRS J. Photogramm. Remote Sens $\mathbf{5 6}$ 177-194.

Gallant J C and Wilson J P 1996 TAPES-G: A grid based terrain analysis program for the environmental sciences; Comput. Geosci. 22(7) 713-722.
Gómez Gutiérrez A, Schnabel S, Lavado Contador F and García Marín R 2011 Testing the quality of open-access DEMs and their derived attributes in Spain: SRTM, GDEM and PNOA DEM; In: Geomorphometry (eds) Hengl T, Evans I S, Wilson J P and Gould M, Redlands CA 53-56.

Grodecki J and Gene D 2003 Block adjustment of high resolution satellite images described by rational polynomials; Photogramm. Eng. Remote Sens. 69(1) 59-68.

Guth P L 1995 Slope and aspect calculations on gridded digital elevation models: Examples from a geomorphometric toolbox for personal computers; Zeitschrift Geomorph. N.F. Suppl.-Bd. 101 31-52.

Guth P L 2006 Geomorphometry from SRTM - comparison to NED; Photogramm. Eng. Remote Sens. 72(3) 269-277.

Hohle J 2009 DEM generation using a digital large format frame camera; Photogramm. Eng. Remote Sens. 75(1) 87-93.

Holmes K W, Chadwick O A and Kyriankidis P C 2000 Error in USGS 30-meter digital elevation model and its impact on terrain modelling; J. Hydrol. 233 154-173.

Huggel C, Caplan-Auerbach J, Gruber S, Monia B and Wessels R 2008 The 2005 Mt. Steller, Alaska, rock-ice avalanche: Large slope failures in cold permafrost; In: Proceedings of the Ninth International Conference on Permafrost, 29 June-3 July 2008, Fairbanks, AK, pp. 747-752.

Iwahashi J, Watanabeb S and Furuyac T 2003 Mean slopeangle frequency distribution and size frequency distribution of landslide masses in Higashikubiki area, Japan; Geomorphology 50(4) 349-364.

Jain S K and Singh V P 2003 Water Resources Systems Planning and Management 51, 858p.

Januchowski S R, Pressey R L, VanDerWal J and Edwards A 2010 Characterizing errors in digital elevation models and estimating the financial costs of accuracy; Int. J. Geogr. Info. Sci. 24(9) 1327-1347.

Kervyn F 2001 Modelling topography with SAR interferometry: Illustrations of a favourable and less favourable environment; Comput. Geosci. 27 1039-1050.

Mukherjee S, Garg R D and Mukherjee S 2011 Effect of systematic error on DEM and its derived attributes: A case study on Dehradun area using Cartosat-1 stereo data; Ind. J. Landscape System and Ecological Studies 34(1) $45-58$.

Mukherjee S, Mukherjee S, Garg R D, Bhardwaj A and Raju P L N 2013a Evaluation of topographic index in relation to terrain roughness and DEM grid spacing; J. Earth Syst. Sci. 122(3) 869-886.

Mukherjee S, Joshi P K, Mukherjee S, Ghosh A, Garg R D and Mukhopadhyay A 2013b Evaluation of vertical accuracy of open source Digital Elevation Model (DEM); Int. J. Appl. Earth Obser. Geoinfo. 21 205-217.

Raaflaub L D and Collins M J 2006 The effect of error in gridded digital elevation models on the estimation of topographic parameters; Environ. Modell. Software 21 710-732.

Rodgriguez E, Morris C and Belz J 2006 A global assessment of SRTM performance; Photogramm. Eng. Remote Sens. 72 249-260.

San B T and Suzen M L 2005 Digital elevation model (DEM) generation and accuracy assessment from ASTER stereo data; Int. J. Remote Sens. 26(22) 5013-5027.

Schenk T 1996 Digital aerial triangulation; Arch. Photogramm. Remote Sens. 31(B3) 735-745.

Shannon C E 1948 A mathematical theory of communication; Bell System Technical J. 27 379-443.

Taud H, Parrot J and Alvarez R 1999 DEM generation by contour line dilation; Comput. Geosci. 25(7) 775-783. 
Vassilopouloua S, Hurnia L, Dietrichb V, Baltsaviasc E, Paterakic M, Lagiosd E and Parcharidis L 2002 Orthophot generation using IKONOS imagery and high resolution DEM: A case study on volcanic hazard monitoring of Nisyros Island (Greece); ISPRS J. Photogramm. Remote Sens. 57 24-38.

Vieux B E 1993 DEM aggregation and smoothing effect on surface run-off modelling; J. Comput. Civil Eng.-ASCE 7(3) 310-338.

Vieux B E and Farajalla N S 1994 Capturing the essential spatial variability in distributed hydrological modelling: Hydraulic roughness; Hydrol. Process. 8(3) 221-226.

Wilson J P and Gallant J C 2000a Digital terrain analysis; In: Terrain Analysis: Principles and Applications (eds) Wilson J P and Gallant J C, John Wiley \& Sons, New York, pp. 1-27.
Wilson J P and Gallant J C 2000b Terrain Analysis: Principles and Applications; New York: Wiley, 479p.

Wise S 2012 Information entropy as a measure of DEM quality; Comput. Geosci. 48 102-110.

Wolock D M and Price C V 1994 Effects of digital elevation model map scale and data resolution on a topographybased watershed model; Water Resour. Res. 30(11) 3041-3052.

Wu S, Li J and Huang G H 2008 A study on DEM-derived primary topographic attributes for hydrological applications: Sensitivity to elevation data resolution; Appl. Geogr. 28 210-223.

Zhang W and Montgomery D R 1994 Digital elevation model grid size, landscape representation, and hydrologic simulation; Water Resour. Res. 30(4) 10191028 .

MS received 3 May 2014; revised 19 October 2014; accepted 16 November 2014 